\title{
Dynamic Characterization of Fiber Optical Chirped Pulse Amplification for Sub-ps Pulses
}

\author{
Cristofori, Valentina; Lali-Dastjerdi, Zohreh; Rishøj, Lars Søgaard; Galili, Michael; Peucheret, \\ Christophe; Rottwitt, Karsten
}

Published in:

Nonlinear Optics Technical Digest

Publication date:

2013

Document Version

Publisher's PDF, also known as Version of record

Link back to DTU Orbit

Citation (APA):

Cristofori, V., Lali-Dastjerdi, Z., Rishøj, L. S., Galili, M., Peucheret, C., \& Rottwitt, K. (2013). Dynamic Characterization of Fiber Optical Chirped Pulse Amplification for Sub-ps Pulses. In Nonlinear Optics Technical Digest (pp. NW4A.07). Optical Society of America.

\section{General rights}

Copyright and moral rights for the publications made accessible in the public portal are retained by the authors and/or other copyright owners and it is a condition of accessing publications that users recognise and abide by the legal requirements associated with these rights.

- Users may download and print one copy of any publication from the public portal for the purpose of private study or research.

- You may not further distribute the material or use it for any profit-making activity or commercial gain

- You may freely distribute the URL identifying the publication in the public portal 


\title{
Dynamic Characterization of Fiber Optical Chirped Pulse Amplification for Sub-ps Pulses
}

\author{
Valentina Cristofori, Zohreh Lali-Dastjerdi, Lars Søgaard Rishøj, Michael Galili, \\ Christophe Peucheret and Karsten Rottwitt \\ Department of Photonics Engineering, Technical University of Denmark, DK-2800 Kgs. Lyngby, Denmark \\ vari@fotonik.dtu.dk
}

\begin{abstract}
We investigate experimentally the propagation of sub-picosecond pulses in fiber optical parametric chirped pulse amplifiers, showing a significant broadening of the pulses from $450 \mathrm{fs}$ up to $720 \mathrm{fs}$ due to dispersion and self-phase modulation.
\end{abstract}

(C) 2013 Optical Society of America

OCIS codes: $190.4970,060.2320$.

Optical amplification of signals reaching multi-terabit per second per channel is becoming increasingly relevant following the recent demonstrations of single wavelength channel systems at bit rates of $1.28 \mathrm{Tbit} / \mathrm{s}, 5.1 \mathrm{Tbit} / \mathrm{s}$ or even $10.2 \mathrm{Tbit} / \mathrm{s}[1,2]$, all using ultra-short pulses on the order of $500 \mathrm{fs}$. Therefore, a broadband amplification scheme is required for such wide bandwidth signals. Fiber optical parametric amplifiers (FOPAs) relying on highly nonlinear fibers (HNLFs) are promising candidates thanks to their inherent compatibility with fiber optic systems and their ability to provide gain over a broad bandwidth, limited only by fulfillment of the phase matching condition. Fiber optical parametric chirped pulse amplification (FOPCPA) in the picosecond [4] and subpicosecond [5] regime has been demonstrated. However, a detailed characterization of the distortion of the pulses due to the interaction between dispersion and self-phase modulation (SPM) in FOPCPAs has, to our knowledge, never been reported. The characterization of these effects is crucial for the achievement of parametric amplification of Tbaud single wavelength channel signals. In this work, we report an experimental characterization of dynamics of sub-picosecond pulses resulting from the amplification process in FOPCPAs. A 400 fs pulse is stretched, propagated through the HNLF without amplification and then compressed back to $450 \mathrm{fs}$. Afterwards, the distortion of the amplified pulses is characterized for different amplification levels. More specifically, the widths and features of the pulses are examined in the saturated as well as unsaturated regime.

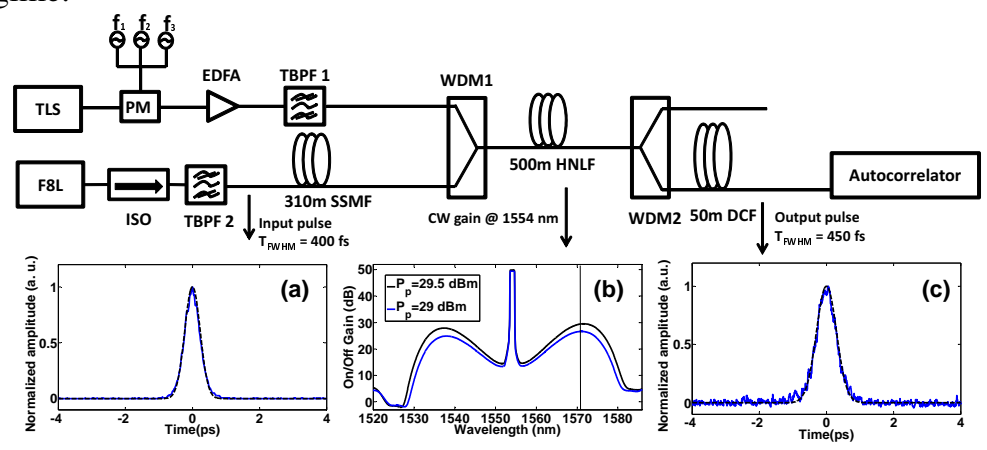

Fig. 1. Experimental setup of the FOPA. a) Autocorrelation trace of the $400 \mathrm{fs}$ input pulse; (b) CW FOPA gain for two different pump levels (the vertical line indicates the signal central wavelength); (c) compressed output pulse autocorrelation without amplification.

The experimental setup is shown in Fig. 1. A continuous wave (CW) tunable laser source (TLS) is used as pump source $\left(\lambda_{p}=1554 \mathrm{~nm}\right)$ and the emitted light is subsequently phase modulated to broaden the pump spectrum to increase the stimulated Brillouin scattering (SBS) threshold. The pump is then amplified in an erbium-doped fiber amplifier (EDFA) and a tunable optical bandpass filter (TBPF1) with a $0.8 \mathrm{~nm}$ full-width at half-maximum (FWHM) bandwidth is used to suppress the out-of-band amplified spontaneous emission (ASE) noise introduced by the EDFA. The signal is generated by a figure-of-eight (F8L) mode-locked laser [6], filtered with a $9 \mathrm{~nm}$ broadband filter (TBPF2) to generate Gaussian pulses at $1571.6 \mathrm{~nm}$ with a FWHM of $400 \mathrm{fs}$ FWHM $28 \mathrm{MHz}$ repetition rate. The signal pulses are stretched to approximately $50 \mathrm{ps}$ in $310 \mathrm{~m}$ of standard single mode fiber (SSMF) in order to avoid saturation or supercontinuum generation [6]. They are then combined with the pump via a wavelength division multiplexer (WDM1) 
into a $500 \mathrm{~m}$ long HNLF, with zero-dispersion wavelength of $1550.4 \mathrm{~nm}$, non-linear coefficient of $10.7 \mathrm{~W}^{-1} \cdot \mathrm{km}^{-1}$ and dispersion slope of $0.018 \mathrm{ps} /\left(\mathrm{nm}^{2} \cdot \mathrm{km}\right)$. The amplified signal is filtered by the WDM2 and then compressed with a $50 \mathrm{~m}$ long dispersion compensating fibre (DCF), with a total dispersion of $5.89 \mathrm{ps} / \mathrm{nm}$ at $1550 \mathrm{~nm}$. The pulsewidth of the compressed signal is measured using an autocorrelator.

Fig. 2 (a) and (b) show the measured FWHM pulsewidths $\left(T_{F W H M}\right)$ when the input pump power and the input signal
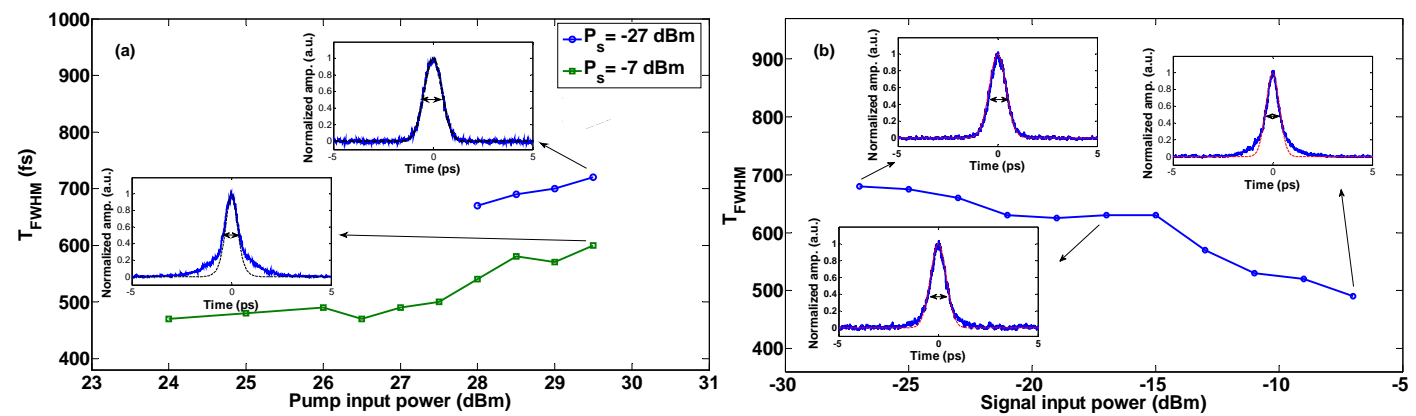

Fig. 2. Pulsewidth of the amplified signal (a) as a function of pump power in the saturated and unsaturated regimes and (b)as a function of the input signal power with a pump power of $29 \mathrm{dBm}$. The insets show selected autocorrelation traces.

power are changed, respectively. It can be seen from Fig. 2 (a) how the pulsewidth increases with increasing pump power, i.e. increasing gain, both in the saturated and unsaturated regimes. The insets show the autocorrelation traces fitted with Gaussian functions. When the FOPCPA is saturated, side lobes appear on the pulses, causing discrepancies with the Gaussian fit. In Fig. 2 (b) it is noticed that the $T_{F W H M}$ decreases as the signal power is increased, while the side lobes appear as saturation is gradually reached. It is speculated that the side lobes are due to the interplay between SPM and higher order dispersion in the FOPCPAs, reshaping the pulses and producing a narrowing of the pulses, instead of broadening due to saturation of the amplifier.

In summary, characterization of the amplification of short nearly transform-limited pulses of 9 nm bandwidth and 400fs pulse duration in a FOPCPA configuration has been presented, for the first time. The 400 fs pulses were stretched to $50 \mathrm{ps}$, propagated through the FOPA and then compressed back to $450 \mathrm{fs}$. The effect of amplification was characterized when pumping the HNLF with different pump power levels. In particular, it was shown that the pulse FWHM is increasing with increasing gain from $450 \mathrm{fs}$ to $720 \mathrm{fs}$ in unsaturated regime and to 600 fs in saturated regime. However, the pulsewidths compressed as saturation was reached and this shortening is expected to be due to the interplay between SPM and high order dispersion in the amplifier. The characterization of the effects caused by the amplification is crucial for the compensation of pulse broadening, hereby enabling parametric amplification of Tbaud single wavelength channel signals.

\section{Acknowledgment}

OFS Fitel Denmark is acknowledged for providing the fibers. The Danish Research Council for Technology and Production Sciences is acknowledged for financial support (project 09-066562).

\section{References}

1. H. C. Hansen Mulvad et al., "1.28 Tbit/s single-polarisation serial OOK optical data generation and demultiplexing," Electron. Lett., 45, pp. 280-281, (2009)

2. T. Richter et al., "Transmission of single-channel 16-QAM data signals at Terabaud symbol rates," J. Lightwave Technol., 30, pp. 504-511, (2012).

3. M. Hanna et al., "Fiber optical parametric chirped-pulse amplification in the femtosecond regime," Opt. Express, 35, pp. 1786-1788, (2011).

4. D. Caucheteur et al., "Experimental demonstration of optical parametric chirped pulse amplification in optical fiber," Opt. Express, 35, pp. 1786-1788, (2011).

5. Y. Zhou et al., "All-fiber based ultrashort pulse generation and chirped pulse amplification through parametric processes," IEEE Photon. Technol. Lett., 22, pp. 1330-1332, (2010).

6. L. Grüner-Nielsen, B. Pálsdóttir, "Highly nonlinear fibers for very wideband supercontinuum generation,” Proc. of SPIE, 6873, (2008). 